\title{
The effects of Carbogen, carbon dioxide, and oxygen on noise-induced hearing loss
}

\author{
Mark Hatch, Mary Tsai, Michael J. LaRouere, Alfred L. Nuttall and Josef M. Miller \\ University of Michigan Medical School, Ann Arbor, Michigan, U.S.A.
}

(Received 16 March 1991; accepted 20 July 1991)

\begin{abstract}
An investigation into the effect of Carbogen $\left(95 \% \mathrm{O}_{2} / 5 \% \mathrm{CO}_{2}\right), 5 \% \mathrm{CO}_{2} /$ air, and $100 \%$ oxygen on cochlear threshold shifts caused by noise was undertaken. Five groups of eight pigmented guinea pigs were exposed to $105 \mathrm{~dB}$ broad band noise for $6 \mathrm{~h}$ per day for five consecutive days with each group receiving the various gaseous mixtures either during noise exposure or for $1 \mathrm{~h}$ immediately after noise exposure. A control group received the same noise exposure but respired air. Auditory threshold shifts, as measured by the auditory evoked brainstem response, were measured at $2,4,8,12,16,20$ and $24 \mathrm{kHz}$. Recordings were taken pre-exposure and at Day 1, 3, 5, and Weeks 2 and 3 after noise exposure. Carbogen, given during noise exposure, resulted in a trend toward less post noise exposure threshold shift (as compared to controls) which reached statistical significance by Week 3 at all frequencies except 2 and $20 \mathrm{kHz}$. Subjects given Carbogen after exposure also showed a general trend toward decreased noise induced threshold shifts, as compared to controls, but this was not statistically significant. The mixture of $5 \%$ $\mathrm{CO}_{2}$ /air given during noise exposure yielded no difference in threshold shifts as compared to controls. When $100 \%$ oxygen was administered during noise exposure, a marked decrease in noise induced threshold shifts could be seen as compared to controls, with differences reaching statistical significance by day 5 at most frequencies. These results indicate that oxygen (i.e. cochlear-oxygenation) is a more important factor than $\mathrm{CO}_{2}$ (i.e., as a vasodilator) in protection of the cochlea from noise induced damage.
\end{abstract}

Guinea pig; Auditory brainstem response; Temporary threshold shift; Temperature

\section{Introduction}

It has been suggested that noise induced hearing loss (Hawkins, 1971; Axelsson and Vertes, 1982), sudden hearing loss (Johnson and Hawkins, 1972), and other inner ear disorders (Vertes et al., 1979; Nuttall et al., 1981) are attributable to vascular insufficiency in the inner ear. A vascular theory of noise-induced hearing loss has been supported by several studies in the past which have demonstrated narrowing of cochlear vessels (Hawkins et al., 1972), decreased cochlear oxygen tension (Misrahy et al., 1958; Thorne and Nuttall, 1987a), decreased laser Doppler recorded flow (Thorne and Nuttall, 1987b) and poor penetration of contrast media (Lipscomb et al., 1977) in the cochlea vasculature during sound exposure.

Many manipulations to increase blood flow to the cochlea have been studied. These include vasoactive agents (Miller et al., 1983; Suga and Snow, 1969), hemodilution (Hultcrantz and Nuttall, 1987; Kellerhals, 1972), sympathectomy (Hultcrantz et al., 1977), drugs such as Pentoxifylline (Quirk et al., 1988) and carbon dioxide (Witter et al., 1980; Joglekar et al.,

Correspondence to: Alfred L. Nuttall, University of Michigan Medical School, Kresge Hearing Research Institute, 1301 East Ann Street, Ann Arbor, MI 48109-0506, U.S.A.
1977; Brown et al., 1982, 1985) The current investigation focuses on the effect of the gaseous agent Carbogen $\left(95 \% \mathrm{O}_{2}, 5 \% \mathrm{CO}_{2}\right)$ and its components, $5 \% \mathrm{CO}_{2}$ and $100 \% \mathrm{O}_{2}$, on threshold shifts caused by noise-induced cochlear damage.

Previous experiments have been performed on Carbogen's effect of temporary and permanent threshold shifts (TTS and PTS). Witter et al. (1980) demonstrated a reduced maximal TTS and a more rapid rate of recovery in chinchillas pretreated with Carbogen while Joglekar et al. (1977) showed a decrease in the TTS in both chinchillas and humans given either Car-

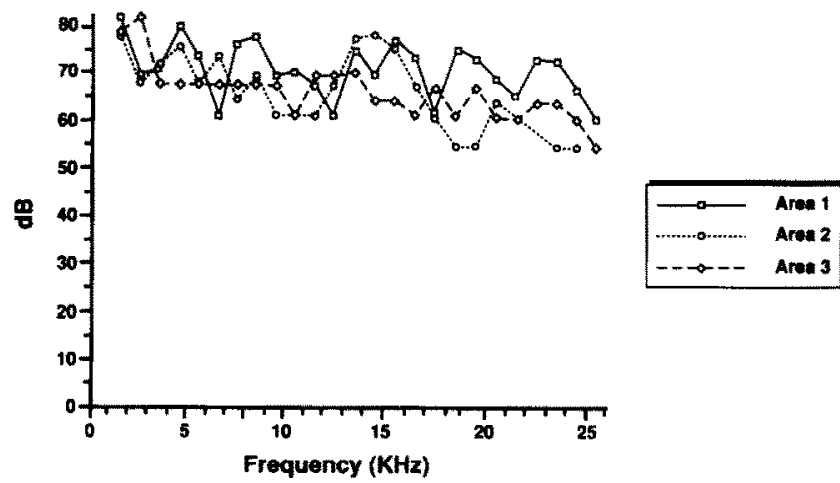

Fig. 1. Sound pressure levels expressed in dB SPL measured at three different locations within the sound chamber. Levels are noted to be similar at each area across all frequencies $(1-30 \mathrm{kHz})$. 
bogen or $100 \%$ oxygen, during or after noise exposure. The greatest effect in threshold shifts was seen in the Carbogen group. Brown et al. $(1982,1985)$ showed a decrease in PTS in guinea pigs given Carbogen during $120 \mathrm{~dB}$ broad band noise exposure. They also found significantly less outer hair cell loss in the Carbogen group as compared to controls.

These studies are consistent with the view that Carbogen provides a protective function from hypoxic injury that may result from a noise induced vascular compromise. It is reasonable to hypothesize that the $\mathrm{CO}_{2}$ in Carbogen is the active factor producing an increased blood flow to the cochlea, thus increasing oxygen availability.

A study by Hultcrantz et al. (1980) compared increases in cochlear blood CBF flow between Carbogen and $\mathrm{CO}_{2}$ /air using microsphere technique. There was a $115 \%$ increase in CBF after $5 \mathrm{~min}$ in the $\mathrm{CO}_{2} /$ air group as compared to $29 \%$ increase in the Carbogen group. Moreover, $30 \mathrm{~min}$ after exposure there was still improved blood flow to the cochlea in the $\mathrm{CO}_{2} /$ air group as compared to the Carbogen group $(52 \%$ vs. $44 \%$ ). It would seem that $\mathrm{CO}_{2} /$ air might also provide an equivalent or even enhanced protective effect on noise-induced cochlear damage. With this in mind, a study was performed to compare the effect of both Carbogen and its components on noise-induced hearing loss.

\section{Materials and Methods}

Male and female albino guinea pigs weighing between 200 and 250 grams with normal Preyer reflexes were used in the study. The study was performed in two phases. In phase 1 , two groups of animals (each with $N=8$ ) received Carbogen gas $\left(95 \% \mathrm{O}_{2}, 5 \% \mathrm{CO}_{2}\right)$; one group receiving Carbogen during noise exposure, and one group receiving Carbogen for a period of $1 \mathrm{~h}$ immediately after noise exposure. A third group ( $N=$ 4) were room air breathing controls. In phase 2 , one group of animals $(N=8)$ received $5 \% \mathrm{CO}_{2}$ in air during noise exposure, and a second group $(N=8)$ received $100 \% \mathrm{O}_{2}$ during noise exposure, and an additional control group $(N=8)$ breathed room air while exposed to noise. In all cases the animals were awake
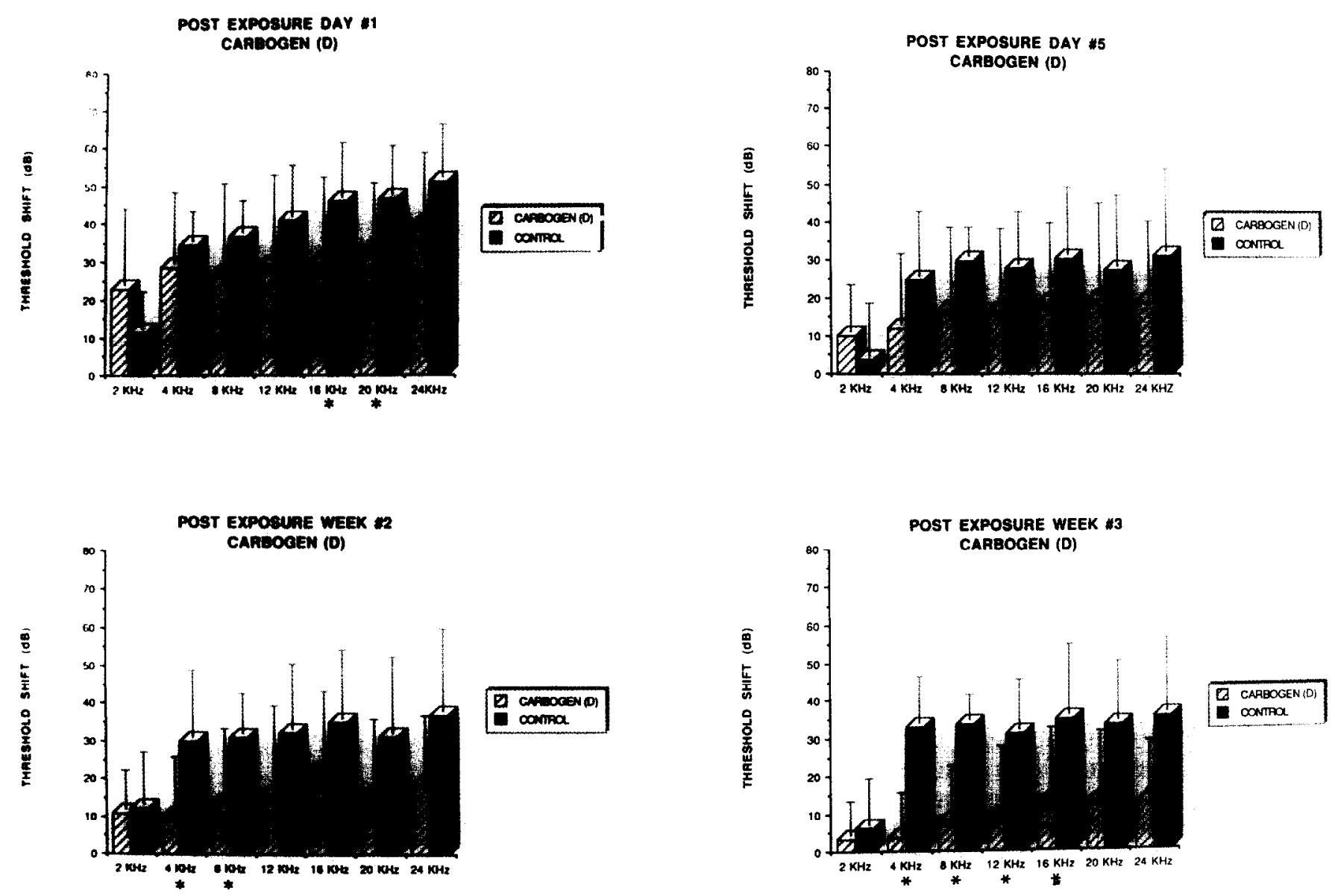

Fig. 2. Mean threshold shifts in animals $(N=8)$ breathing Carbogen during noise exposure [Carbogen (D)] as compared to airbreathing controls $(N=8)$, from 2 to $24 \mathrm{kHz}$. An improvement in the hearing levels can readily be seen in the Carbogen group as compared to controls, especially at Weeks 2 and 3 . $^{*}$ denotes $P \leqq 0.05$. Vertical bars indicate one standard deviation above and below the mean. 
and freely respired the gas mixtures under normal atmospheric pressure.

All animals were subjected to $105 \mathrm{~dB}$ SPL broadband noise for $6 \mathrm{~h}$ per day on five consecutive days. A sound chamber was used fitted with speakers driven by a noise generator (band width $=1-30 \mathrm{kHz}$ ) and power amplifier. The chamber was lighted and ventilated. Animals were placed in separate cages and positioned in different areas daily to insure equal exposure. Sound levels were measured at 3 different locations within the sound chamber using a flat weighted sound level meter. Sound spectrum levels (determined with a wave analyzer) were similar at each location (Fig. 1). The concentration of administered gases was monitored and kept constant with the aid of $\mathrm{CO}_{2}$ and $\mathrm{O}_{2}$ analyzers which sampled the gas at a central level in the chamber. Measurements made at various locations within the chamber showed that the gas concentration distribution was uniform. The delivered gases and that exhaled by the animals escaped from the chamber through ventilation holes.

Auditory evoked brainstem responses (ABR) were measured prior to noise exposure and on Days $1,3,5$ and Weeks 2 and 3 after noise exposure. Animals were anesthetized with a mixture of Xylazine $(5 \mathrm{mg} / \mathrm{kg}$ ) and Ketamine $(30 \mathrm{mg} / \mathrm{kg})$ given intramuscularly prior to ABR. Differential active needle electrodes were placed subcutaneously at the vertex and left ear. A ground electrode was positioned near the contralateral ear. The sound stimulus consisted of a $15 \mathrm{~ms}$ tone burst with a rise-fall time of one millisecond, at frequencies $2,4,8,12,16,20$ and $24 \mathrm{kHz}$. Two hundred fifty-six tone presentations were averaged using a microcomputer and custom software to obtain a waveform. ABR threshold was defined in this study as a sound level producing a distinctly noticeable wave $\mathrm{V}$ on the $\mathrm{ABR}$ (i.e. a peak waveform deflection of approximately $1 \mu \mathrm{v}$ referred to the animal).

\section{Results}

The mean ABR threshold shifts observed in animals breathing Carbogen during and after noise exposure compared to a control (air breathing) group are shown in the bar graphs in Figs. 2 and 3, respectively. The
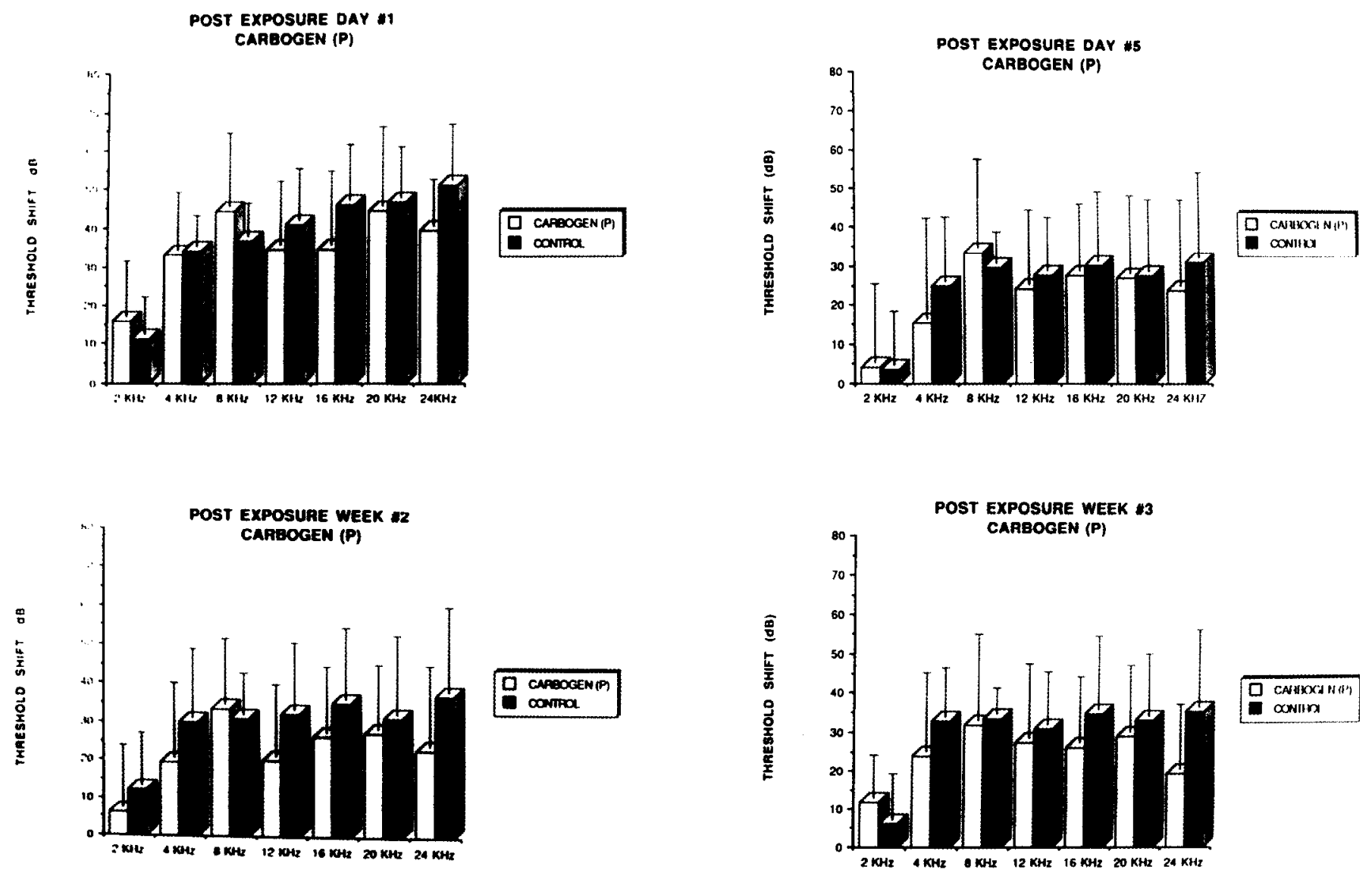

Fig. 3. Mean threshold shifts in animals $(N=8)$ breathing Carbogen after noise exposure for $1 \mathrm{~h}$ [Carbogen (P)] as compared to airbreathing controls $(N=8)$. Although there is a slight improvement in this group as compared to controls, no statistically significant difference exists. Vertical bars indicate one standard deviation above and below the mean. 
$y$-axis of each graph represents the threshold shift (post-exposure A.B.R. - pre-exposure A.B.R). The $x$ axis gives the frequencies tested. Threshold shifts observed on Days 1 and 5 and Weeks 2 and 3 following exposure are shown. In Fig. 2 one can see that at Day 1 post exposure, when Carbogen was given during noise exposure, there is a smaller threshold shift as compared to controls over all frequencies except $2 \mathrm{kHz}$. During the following 3 weeks, an improvement in the hearing levels can be seen in both the Carbogen (D) and control group with the greatest recovery seen in the Carbogen (D) group. This is most evident at Week 2 and 3 post exposure, whereby the difference in the two groups is statistically significant for 4 of the 7 frequencies tested. When Carbogen was given post exposure (Fig. 3), although there is a trend toward improvement in the threshold shifts in the Carbogen (P) group, no statistically significant difference compared to controls was demonstrated at any frequency, even when followed over time.

An examination of three individual frequencies (Fig. 4), demonstrated a trend toward continued improvement over time to near normal levels in the group given Carbogen during noise exposure as compared to the other two groups.

The results of the second phase of the study are shown in Figs. 5-8. A scparate group of animals was exposed to either $5 \% \mathrm{CO}_{2}$ /air or $100 \%$ oxygen during noise exposure and were compared to a separate group of controls. As seen in Fig. 5, 5\% $\mathrm{CO}_{2} /$ air given during noise exposure showed only small and statistically insignificant differences in threshold shifts as compared to the control group.

In contrast to the $\mathrm{CO}_{2}$ /air group, the oxygen-treated group (Fig. 6) had significantly less threshold shifts than controls, this being readily evident by Day 5 post noise exposure. These results were clearly demonstrated in a graph of the temporal pattern of change for the individual frequencies (Fig. 7). Again, a marked improvement in threshold shifts can be seen in the $100 \%$ oxygen group as compared to either the $\mathrm{CO}_{2} /$ air or control group when followed over the weeks of study.

Fig. 8 compares the differences in threshold shift between the controls and the individual gases across the duration of the study. Seen at Weeks 2 and 3 post-exposure, there is a greater than $50 \mathrm{~dB}$ difference between the control and oxygen group. This compares to a $22 \mathrm{~dB}$ difference in the Carbogen (D) group and a $14 \mathrm{~dB}$ difference in the $\mathrm{CO}_{2}$ /air group and a $7 \mathrm{~dB}$ difference in the Carbogen $(P)$ group at Week 3.

\section{Discussion}

The results of this investigation confirm the beneficial effect of oxygen (both as $100 \% \mathrm{O}_{2}$ and Carbogen)
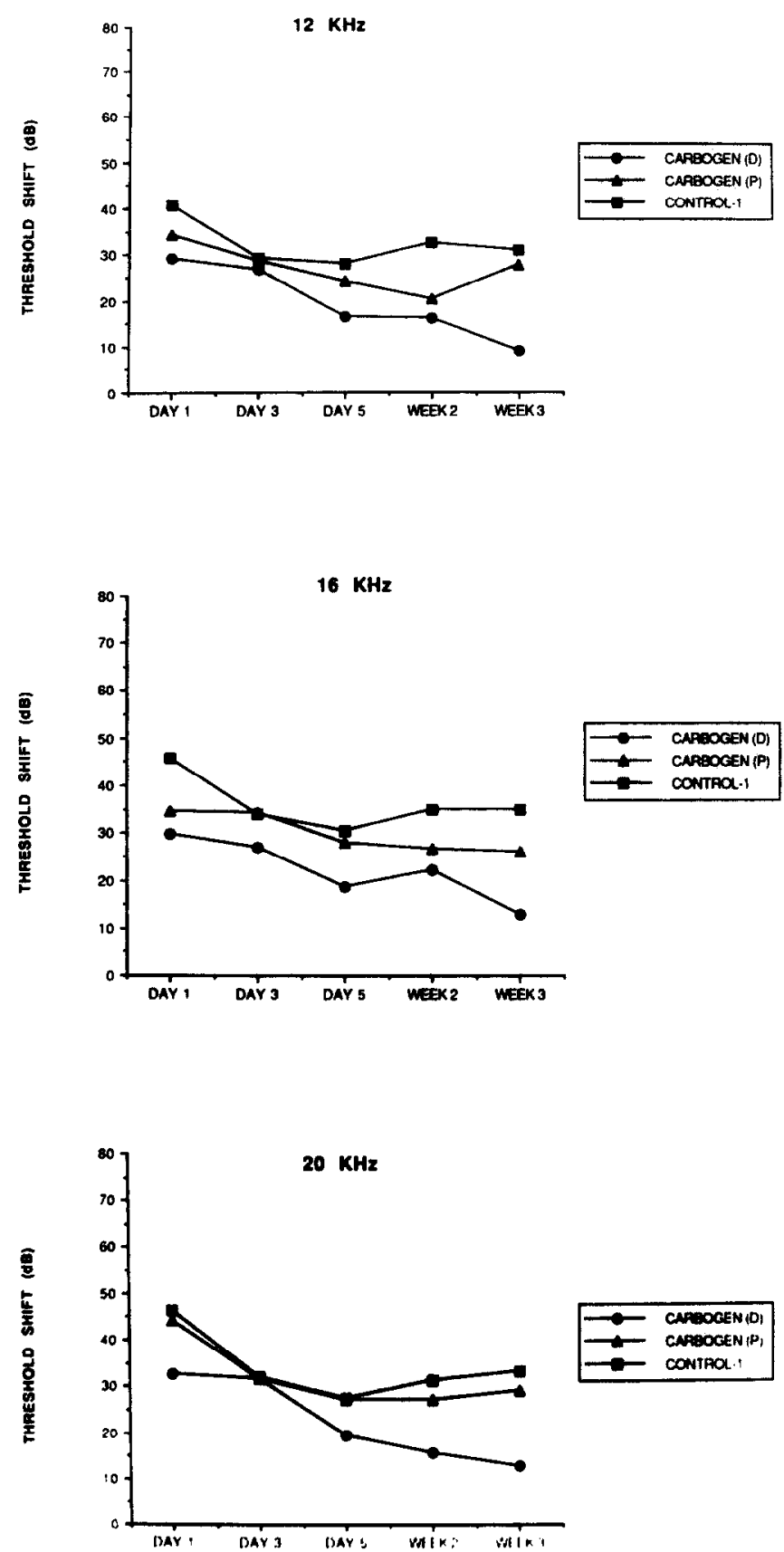

Fig. 4. Mean threshold shifts in the Carbogen groups ( $N=8$ each) and control group $(N=8)$ plotted against time (Day 1 post-exposure to Week 3 post-exposure) for frequencies 12,16 , and $20 \mathrm{kHz}$. A trend toward continued improvement, and an overall improved threshold shift, can be seen in the Carbogen (D) group as compared to the Carbogen (P) group and control group.

on noise-induced hearing loss as reported in the previous studies by Brown et al., (1982, 1985), Witter et al. (1980), and Joglekar et al. (1977), when Carbogen was given during noise exposure. In contrast to Joglekar et al. (1977), however, we obtained no statistical significant difference between the control group and the group given Carbogen after noise exposure, although there certainly seems to be a trend toward improved 
threshold shift. This may, in part, be related to the insufficient time of exposure to the gaseous mixture after the acoustic trauma or the exact conditions of the noise exposure itself. Carbogen was administered for a 6-h period, throughout noise exposure in the 'during' group; the 'post-exposure' group breathed the mixture for $1 \mathrm{~h}$.

The theory of Carbogen's beneficial effect is that the $\mathrm{CO}_{2}$, a known vasodilator, acts synergistically with oxygen in Carbogen to produce increased oxygenation of cochlear tissues and reduce cochlear damage. A study by Hultcrantz et al. (1980) did show a marked increase in blood flow to the cochlea when $7 \% \mathrm{CO}_{2} / \mathrm{air}$ mixture was given using the microsphere technique. Previous work has also shown elevated oxygen tension in the endolymph (Prazma et al., 1978) and perilymph (Fisch et al., 1976) with inhalation of 5-10\% $\mathrm{CO}_{2}$. Kallinen et al. (1991) have shown that Carbogen does not decrease the apparent vascular resistance of the cochlea (i.e. give vasodilation) because the dilative effects of $\mathrm{CO}_{2}$ are countered by high arterial levels of oxygen.
Until now, however, no investigations have been undertaken to determine the beneficial effects of the individual components of Carbogen. It would seem that each component might also provide a protective function to the cochlea. Or perhaps the high oxygen component will counteract the supposed vasodilative effect of $\mathrm{CO}_{2}$. As seen in Fig. 5, however, $5 \% \mathrm{CO}_{2}$ in air given during noise exposure showed no beneficial effect on the threshold shifts through the time course of this study.

When $100 \%$ oxygen was administered during the noise exposure, however, a marked improvement in acoustic damage, as measured by $\mathrm{ABR}$, was seen. The oxygen-exposed animals returning to near normal hearing levels by Day 5 post-exposure. The beneficial effects of $\mathrm{O}_{2}$ alone were even greater than when the Carbogen was given. This would seem to suggest that it is the oxygen and not the $\mathrm{CO}_{2}$ in Carbogen that provides the protective effect from acoustic injury within the cochlea.

Studies of cochlear blood flow have indicated that high levels of sound ( $>110 \mathrm{~dB}$ SPL) cause increased
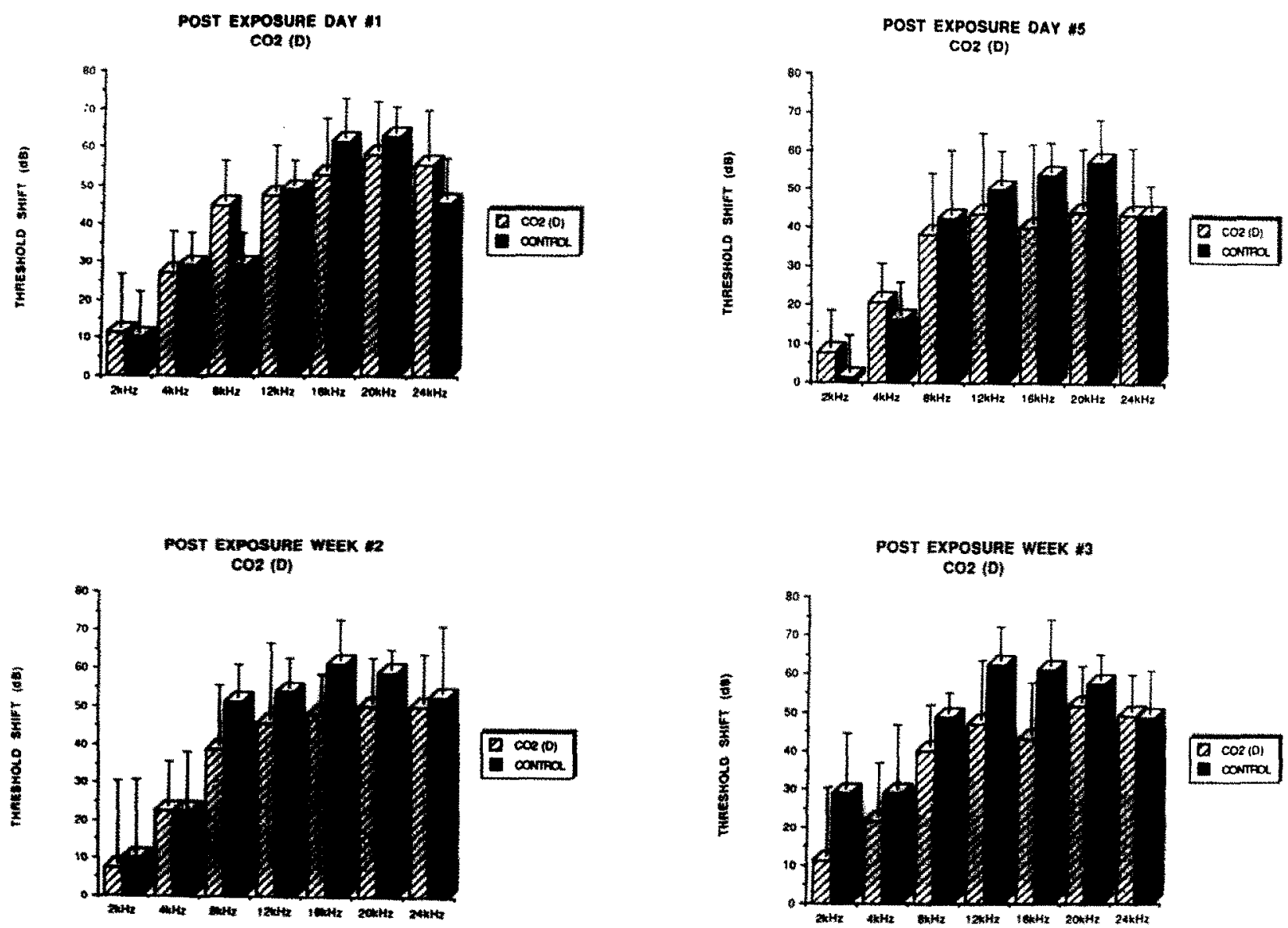

Fig. 5. Mean threshold shifts in the $5 \% \mathrm{CO}_{2} /$ air $/$ breathing group $(N-8)$ compared to controls $(N=4)$. No significant difference between the two groups exists over all frequencies tested. Vertical bars indicate one standard deviation above and below the mean. 
flow (eg. Prazma et al., 1983; Quirk et al., 1990) but the lower levels used in the current study actually decrease the flow (eg. Thorne 1987b) as well as the intracochlear $\mathrm{PO}_{2}$ (eg. Thorne, 1987a). Blood flow changes may also be associated with local metabolic demand as has been strongly suggested by flow increases observed for more moderate sound levels $(<100 \mathrm{~dB}$ SPL) (see Ryan et al., 1982; Quirk et al., 1991).

Kallinen et al. (1991) have shown that guinea pigs freely respiring Carbogen do not have elevated blood arterial $\mathrm{PCO}_{2}$ but do have greatly elevated $\mathrm{PO}_{2}$. That elevated arterial $\mathrm{PO}_{2}$ was associated with vasoconstriction in the cochlea. All of this evidence would suggest that, for the sound intensity used in the current work, the physiological effects of vasoconstriction in the cochlea are offset by improved intracochlear oxygenation.

The current study was conducted over a 6-month interval. The first group of animals tested was the Carbogen group with controls and the second group of animals included the $\mathrm{CO}_{2}$ /air and oxygen group with controls. Despite constant monitoring of sound pressure levels within the sound chamber, there are evident differences in threshold shifts between the two control groups. Post hoc examination of our experiment suggest that a potential variable between these two groups was the temperature in the sound chamber. The temperature in the sound chamber of the Carbogen groups was approximately $5-10$ degrees $\left(20-25^{\circ}\right.$ vs $\left.15^{\circ}\right)$ Celcius cooler than the $\mathrm{CO}_{2} /$ air and oxygen groups. This was due to seasonal differences in the temperature of the building area where the experiment was conducted.

Berndt and Wagner (1981) have shown that lowering of the ambient temperature during noise exposure significantly lessens noise damage to the cochlea in guinea pigs. A similar effect on TTS has been reported in humans (Wright et al., 1981). These studies would be consistent with our data. The control/Carbogen group (exposed when the ambient air was cool) had less threshold shift than the control $\left(\mathrm{CO}_{2}\right.$ and $\left.\mathrm{O}_{2}\right)$
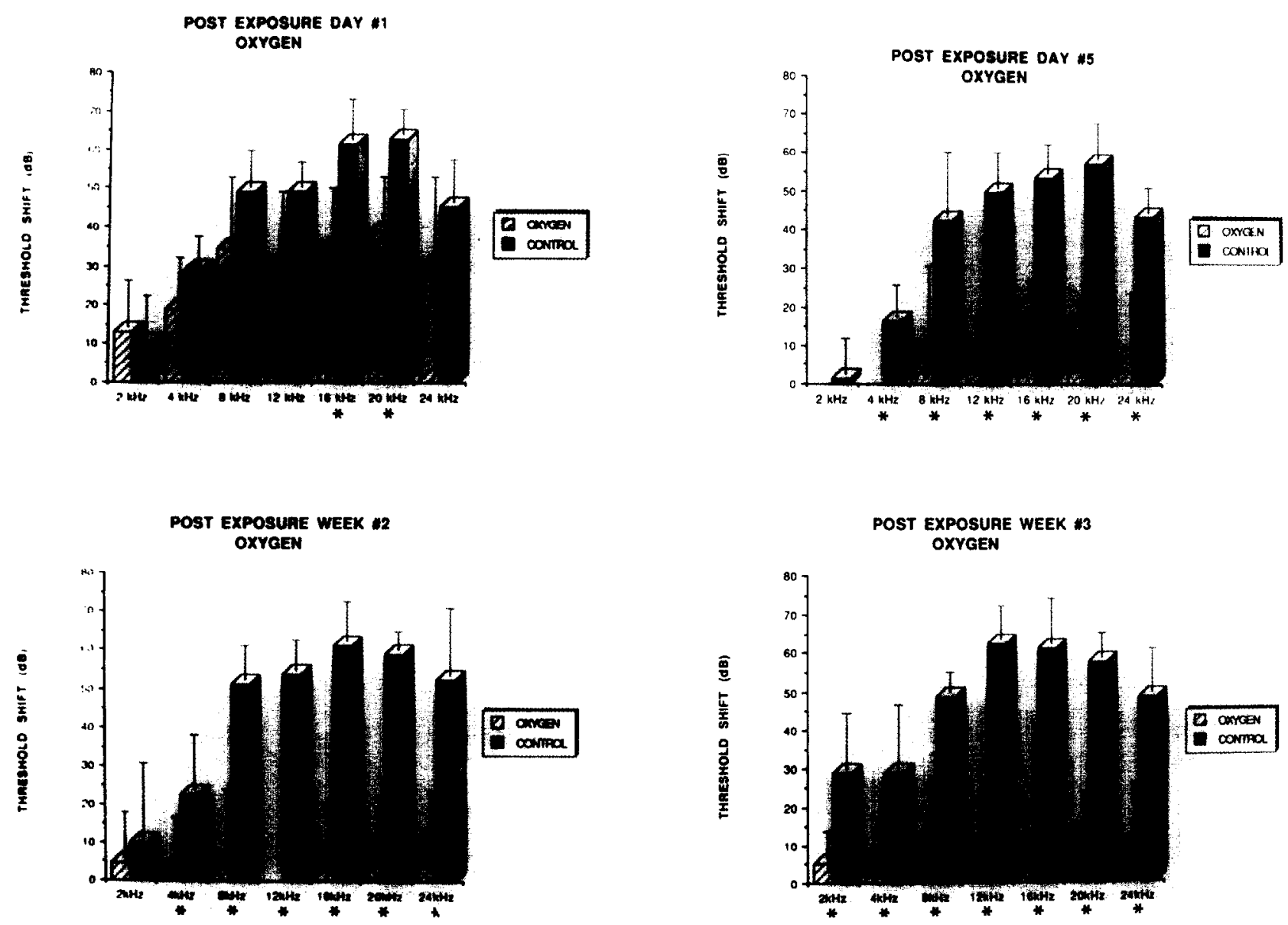

Fig. 6. Mean threshold shifts in the $100 \%$ oxygen breathing group $(,=8)$ as compared to controls $(N=4)$. As can be seen, by Day 5 there is a marked difference in the threshold shifts with the oxygen treated animals' hearing level returning to near normal. ${ }^{*}$ denotes $P \leqq 0.05$. Vertical bars indicate one stand. $\mathrm{d}$ deviation above and below the mean. 
group exposed when the ambient air was warmer. Although there were differences in the control groups for the Carbogen treated animals and the $\mathrm{CO}_{2}$ and $\mathrm{O}_{2}$ treated animals, it is still obvious that there is a marked improvement in hearing levels in the Carbogen and $100 \%$ oxygen group when comparing them to either control group.

Further studies need to be performed on the effect of oxygen given after noise exposure, as these results
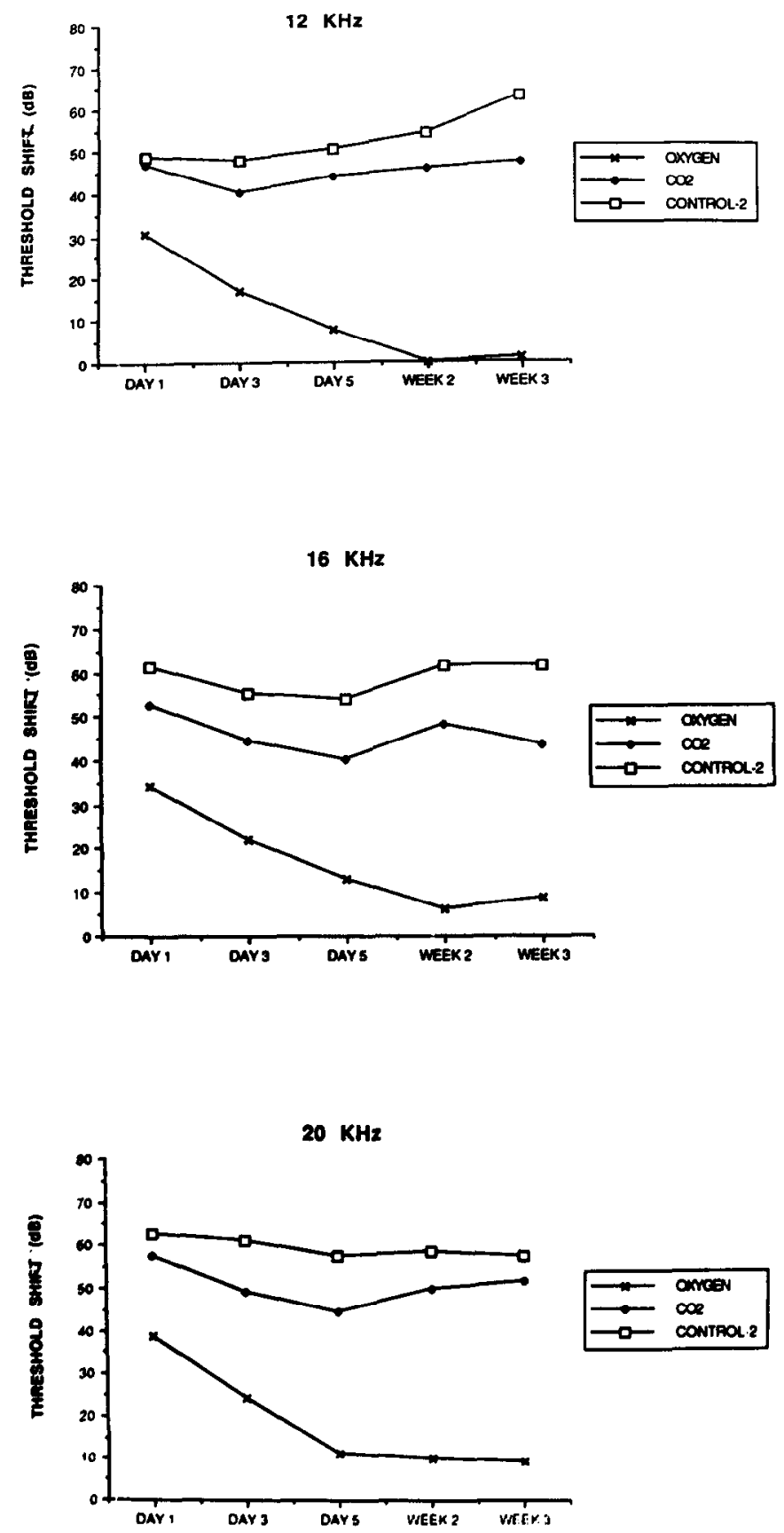

Fig. 7. Mean threshold shifts in the $100 \%$ oxygen group $(N=8), 5 \%$ $\mathrm{CO}_{2}$ group $(N=8)$ and controls $(N=8)$ plotted against time for frequencies 12,16 , and $20 \mathrm{kHz}$. The oxygen-treated animals' threshold shifts are clearly changed as compared to the other two groups.

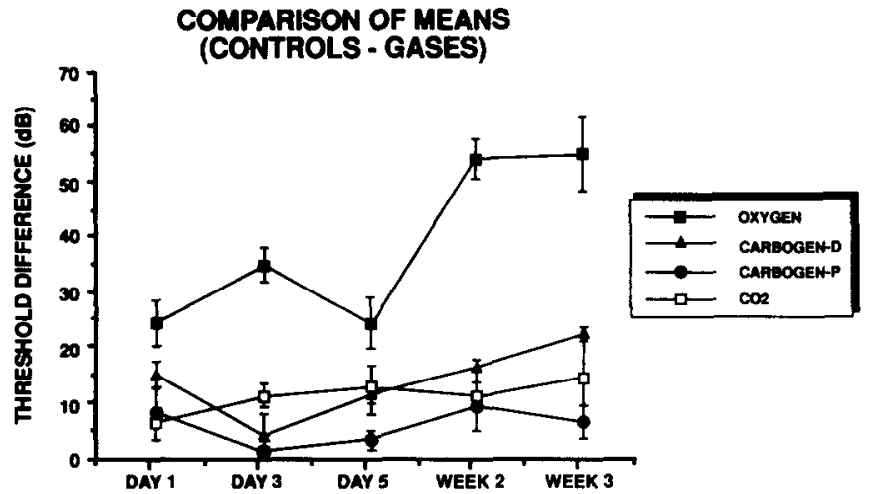

Fig. 8. The mean difference between the threshold shifts of the controls minus the various gases (at 12,16, and $20 \mathrm{kHz}$ ) plotted against time. At especially Weeks 2 and 3, a marked difference can be seen in the oxygen-treated group as compared to the other groups. Vertical bars indicate one standard deviation above and below the mean.

may hold clinical relevance. Perhaps in industry, military, or other occupations where there are excessive amounts of noise exposure, oxygen administration may be of benefit.

\section{Conclusions}

- Carbogen favorably affects threshold shifts that result from noise-induced cochlear damage, with the greatest effect being when Carbogen is given during noise exposure

- $5 \% \mathrm{CO}_{2}$ in air has no benefit on threshold shifts caused from noise exposure

- $100 \%$ oxygen, however, shows a marked improvement in threshold shifts when given during noise exposure

- oxygen (i.e. cochlear oxygenation) is a more important factor than $\mathrm{CO}_{2}$ (as a vasodilator) in protection of the cochlea from noise-induced cochlear damage.

\section{Acknowledgements}

This work was supported by NIH grant DC-00105, RO1-AG8885, and DRF Fellowship for M. Tsai.

\section{References}

Axelsson, A, and Vertes, O. (1982) Histological findings in cochlear vessels after noise. In: R.P. Hamernik, D. Henderson and R. Saki (Eds.), New Perspectives on Noise-Induced Hearing Loss, Raven Press, New York, 49-67.

Berndt, H. and Wagner, H. (1981) Influence of hody temperature as the set-up and recovery of noise-induced cochlear damage. Arch. Otolaryngol. 232, 199-202.

Brown, J.J., Meikle, M.B. and Lee, C.A. (1985) Reduction of acoustically induced auditory impairment by inhalation of carbogen gas 
(temporary pure-tone induced depression of cochlear action potentials). Acta Otolaryngol. 100, 218-228.

Brown, J.J., Vernon, J.A. and Fenwick, J.A. (1982) Reduction of acoustically induced auditory impairment by inhalation of carbogen gas (permanent noise-induced cochlear damage). Acta Otolaryngol. 93, 319-328.

Fisch, V., Murata, K. and Hessli, ,G. (1976) Measurement of oxygen tension in human perilymph. Acta Otolaryngol. (Stockh.) 81, 278.

Hawkins, J.E., Johnson, L.G. and Preston, R.E. (1972) Cochlear microvasculature in normal and damaged ears. Laryngoscope 82 , 1901.

Hawkins, J.E. (1971) The role of vasoconstriction in noise-induced hearing loss. Ann. Otol. Rhinol. Laryngol. 80, 903-913.

I Iultcrantz, E., Linder, J. and Angelborg, C. (1977) Sympathetic effects on cochlear blood flow at different blood pressure levels. Inserm. 68, 271-278.

Hultcrantz, E., Larsen, H.C. and Angelberg, C. (1980) The effect of $\mathrm{CO}_{2}$ breathing on cochlear blood flow. Arch Otolaryngol. 228 , 211-215.

Hulcrantz, E. and Nuttall, A.L. (1987) Effect of hemodilution in cochlear blood flow measured by laser Doppler flowmetry. Am. J. Otolaryngol. 8, 16-22.

Joglekar, S.S., Lipscomb, D.M. and Shambaugh, G.E. (1977) Effects of oxygen inhalation on noise-induced threshold shifts in humans and chinchillas. Arch. Otolaryngol. 103.

Johnson, L.G. and Hawkins, J.E. (1972) Vascular changes in the human inner ear associated with aging. Ann. Otol. Rhinol. Laryngol. 81, 364-375.

Kallinen, J., Didier, A., Miller, J.M. and Nuttall, A.L. (1991) The effect of $\mathrm{CO}_{2}$ and $\mathrm{O}_{2}$ gas mixtures on laser Doppler measured cochlear and skin blood flow in guinea pigs. Hear. Res. 55, $255-262$.

Kellerhals, B. (1972) Acoustic trauma and cochlear microcirculation: an experimental and clinical study on pathogenesis and treatment of inner ear lesions after acute noise exposure. Adv. Otol. Rhinol. Laryngol. 18, 91-168.

Lipscomb, D.M., Axelsson, A. et al. (1977) The effects of high level sound on hearing sensitivity, cochlear sensorineural epithelium and vasculature of the chinchilla. Acta Otolaryngol. 84, 44.

Miller, J.M., Marks, N.J. and Goodwin, P.C. (1983) Laser Doppler measurements of cochlear blood flow. Hear. Res. 11, 385.

Misrahy, G.A., Shinabarger, E.W. and Arnold, J.E. (1958) Changes in cochlear endolymphatic oxygen availability, action potential and microphonics during and following asphxia, hypoxia, and exposure to loud sounds. J. Acoust. Soc. Am. 30, 701.

Prazma, J., Fischer, N.D., Biggers, W.P. and Ascher, D. (1978) The changes with endolymphatic oxygen concentration and the cochlear potentials after short anoxia, hyperoxia and hypercapnia. Ann. Otolaryngol. 84, 622.

Prazma, J., Rogers, G.K. and Pillsbury, H.C. (1983) Cochlear blood flow. Arch. Otolaryngol. 109, $611-615$.

Quirk, W.S., Avinash, G., Nuttall, A.L. and Miller, J.M. (1991) The influence of loud sound on red blood cell velocity and capillary diameter in lateral wall vessels of the guinea pig cochlea. Assoc. Res. Otolaryngol., St. Petersburg Beach, FL, 1991.

Quirk, W.S., Dengerink, H.A., Bademian, M.J., Hall, K.W. and Wright, J.W. (1988) The effects of pentoxifylline on cochlear blood flow in normotensive and spontaneously hypertensive rats. Hear. Res. 36, 175-180.

Quirk, W.S., Nuttall, A.L. and Miller, J.M. (1990) Noise-induced changes in red blood cell velocity and vessel diameter in the lateral wall of the rat cochlea. Assoc. Res. Otolaryngol., Clearwater Beach, FL. 1990.

Ryan, A.F., Goodwin, P., Woolf, N.K. et al. (1982) Auditory stimulation alters the pattern of 2-deoxyglucose uptake in the inner ear. Brain Res. 234, 213-225.

Suga, F. and Snow, J.B. (1969) Andrenergic control of cochlear blood flow. Ann Otol Rhinol Laryngol 78, 358.

Thorne, P.R. and Nuttall, A.L. (1987a) Alterations in oxygenation of cochlear endolymph during loud sound exposure. Acta Otolaryngol. (Stockh.) 107, 71-79.

Thorne, P.R. and Nuttall, A.L. (1987b) Laser Doppler measurements of cochlear blood flow during loud sound exposure in the guinea pig. Hear. Res. 27, 1-10.

Vertes, D., Axelsson, A. and Lipscomb, D.M. (1979) Some vascular effects of noise exposure in the chinchilla cochlea. Arch. Otolaryngol. 224, 97-101.

Witter, H.L., Deka, R.C., Lipscomb, D.M. and Shambaugh, G.E. (1980) Effects of prestimulatory carbogen inhalation on noise-induced temporary threshold shifts in humans and chinchillas. Am. J. Otol. 1, 227-232.

Wright, J.W., Dengerink, H.A., Thompson, P. and Morseth, S. (1981) Plasma angiotensin II changes with noise exposure at three levels of ambient temperature. J. Acoust. Soc. Am. 70, 1353-1356. 